\title{
Lung cancer among asbestos cement workers. A Swedish cohort study and a review
}

\author{
C-G OHLSON' ${ }^{1}$ AND C HOGSTEDT ${ }^{2} 3$
}

From the Department of Occupational Medicine, ${ }^{1}$ Medical Center Hospital, Örebro, and Departments of Occupational Medicine, ${ }^{23}$ National Board of Occupational Safety and Health and Karolinska Hospital, Stockholm, Sweden

ABSTRACT A cohort study of 1176 Swedish asbestos cement workers did not indicate any asbestos related excess mortality. Possible explanations of the negative outcome are relatively low exposure levels and the predominant use of chrysotile in production. Such a tentative conclusion is supported by a review of five mortality studies of workers exposed to asbestos cement that report considerable differences in relative risks for lung cancer. These differences could be explained by various degrees of cumulative exposure, the amount of amphiboles in the production, and methodological shortcomings. A median exposure of 10-20 fibre-years does not seem to cause an increased risk of lung cancer, particularly when only chrysotile is used.

Some studies have indicated that mortality from lung cancer in the asbestos cement industry is lower than in certain other industries where asbestos is handled and dust levels are also usually lower.' It has been suggested that dust from the manufacture and handling of asbestos cement products is less injurious to health than dust from raw asbestos because of the cement. The suggestion receives some support from an experimental study showing that the physical and chemical properties of asbestos cement dust more closely resemble those of cement dust than those of pure asbestos dust. ${ }^{2}$ In the first stage of production, however, sacks of pure asbestos are loaded, unloaded, and put into mixers.

The preliminary results from a Swedish asbestos cement cohort did not indicate an increased risk of lung cancer but the results were difficult to interpret. ${ }^{3}$ There was some indication of excess mortality among those with less than two years of employment. The number of deaths was small, however, and the follow up time for those employed long term was relatively short. The cohort has now been followed up for six years after production ceased and has been supplemented by cancer incidence data in addition to mortality.

\section{Study group and methods}

The company records provided names, date of birth,

Received: 2 July 1984

Accepted: 13 August 1984 and years of employment for all workers ever employed. All men employed for more than three months between 1943 and 1976 were included in the cohort, a total of 1216 men.

The vital status of the 1216 men was checked through national health insurance records, which register everyone living in Sweden by a ten digit identification number based on time of birth. Dead men were traced through the death and burial books of the parishes. Death certificates for these men were checked with the Swedish National Central Bureau of Statistics and the officially determined underlying cause of death has been used. The expected numbers of deaths were calculated by multiplying the person-years of observation within five year age categories during respective single calendar years of the study period by the cause specific and sex specific national death rates until age 79 .

A computer program developed at the University of Linköping for calculations of expected values and relative risks with $95 \%$ confidence intervals, was used. ${ }^{4}$ The WHO recommendations for the classification of underlying causes of death have been followed since 1951 in Sweden and consequently the observation period started that year and ended in 1982. The cancer morbidity in the cohort was checked through the National Cancer Registry which, however, covered only the period 1958-79 at the time of the study. The expected incidence of cancer was calculated in the same way as for mortality. 397 
Table 1 Observed and expected number of deaths 1951-82 for the total cohort before age 80 with no latency time requirement. A total of 26931 person-years

\begin{tabular}{lrcr}
\hline Cause of death & Obs & Exp & SMR \\
\hline All causes & 220 & 214 & 103 \\
Malignant tumours & 44 & 50 & 88 \\
Lung cancer & 11 & 9 & 123 \\
Gastric cancer & 1 & $5 \cdot 9$ & 17 \\
Intestinal cancer & 11 & $5 \cdot 9$ & 186 \\
Cancer of pancreas & 2 & $2 \cdot 2$ & 90 \\
Diseases of circulation & 103 & 98 & 105 \\
Diseases of respiratory tract & 13 & $8 \cdot 5$ & 153 \\
Violent deaths & 34 & 27 & 125 \\
\hline
\end{tabular}

den were excluded from the study. Another 15 could not be found in any of the population registers and have been assumed to be alive to the end of the observation period. Four men died before 1951 and did not enter the study period. Thus the cohort consists of 1176 members and only $1 \%$ have been lost to follow up.

A relatively small proportion were employed for less than one year, $15 \%$ of the cohort. Forty per cent were employed for less than two years and $34 \%$ for more than five years.

\section{Exposure}

Exposure data from the studied industry are scanty for the 1950s and 1960s. Nevertheless, the few measurements which were made indicated a general dust level of $10 \mathrm{mg} / \mathrm{m}^{3}$ before the $1970 \mathrm{~s}$ and half that amount during the 1970s. The fibre concentra- tions averaged $1 \mathrm{fibre} / \mathrm{ml}$ based on several hundred samples from five investigations between 1970 and 1976. As the preparation and handling of the asbestos cement products were similar during the earlier decades but ventilation was inferior, the fibre concentration was estimated to have been twice that level, $2 \mathrm{fibre} / \mathrm{ml}$ in accordance with the total dust measurements. The highest value was 8 fibres $/ \mathrm{ml}$ recorded during 45 minutes in 1970 in the asbestos bag barn.

The vast majority of asbestos used was chrysotile but 630 tons of amosite were used between 1949 and 1951 and 400 tons of crocidolite in 1962. The use of these amphiboles was estimated to be less than $1 \%$ of all asbestos used. No estimates of personal exposure were available for all cohort members but for a subcohort of 125 workers with at least 10 years of employment participating in a voluntary health examination in 1976 the average cumulative exposure was estimated to be about 18 fibre-years. ${ }^{5}$

\section{Results}

There were 220 deaths in the entire cohort under age 80 against 214 expected (SMR 103). The number of person-years was 26931 . Malignant tumours caused death in 44 cases against 50 expected (SMR 88) and lung cancer caused death in 11 cases against nine expected (SMR 123) (table 1). Using a latency requirement of 20 years, the SMR for lung cancer was 158 (9 observed as against $5 \cdot 7$ expected), which is statistically non-significant.

Table 2 Observed and expected number of deaths before age 80 in lung cancer in different categories of employment time with a latency time of 20 years: $95 \%$ confidence interval of the relative risk is given

\begin{tabular}{|c|c|c|c|c|c|c|c|c|}
\hline \multirow[t]{3}{*}{ Cause of death } & \multicolumn{6}{|c|}{ Employment time } & \multirow{2}{*}{\multicolumn{2}{|c|}{ Total }} \\
\hline & \multicolumn{2}{|c|}{$<2$ years } & \multicolumn{2}{|c|}{$2-<5$ years } & \multicolumn{2}{|c|}{$\geqslant 5$ years } & & \\
\hline & Obs & $\operatorname{Exp}$ & Obs & $\operatorname{Exp}$ & Obs & $\operatorname{Exp}$ & Obs & $\operatorname{Exp}$ \\
\hline $\begin{array}{l}\text { Lung cancer } \\
\text { Confidence interval }\end{array}$ & 5 & $\begin{array}{c}1 \cdot 8 \\
0.92-6 \cdot 6\end{array}$ & 3 & $\begin{array}{c}1 \cdot 3 \\
0 \cdot 34-15 \cdot 8\end{array}$ & 1 & $\begin{array}{c}2 \cdot 6 \\
0.001-2 \cdot 1\end{array}$ & 9 & $\begin{array}{c}5 \cdot 7 \\
0 \cdot 72-3 \cdot 0\end{array}$ \\
\hline
\end{tabular}

Table 3 Mortality as SMR before age 80 in different categories of employment time with and without a latency time of 20 years

\begin{tabular}{|c|c|c|c|c|c|c|c|c|}
\hline \multirow[t]{4}{*}{ Cause of death } & \multicolumn{8}{|c|}{ Latency time (years) } \\
\hline & \multicolumn{4}{|l|}{0} & \multicolumn{4}{|l|}{20} \\
\hline & \multicolumn{4}{|c|}{ Exp time (years) } & \multicolumn{4}{|c|}{ Exp time (years) } \\
\hline & $<2$ & $2-<5$ & $\geqslant 5$ & Total & $<2$ & $2-<5$ & $\geqslant 5$ & Total \\
\hline $\begin{array}{l}\text { All causes } \\
\text { Malignant tumours } \\
\text { Diseases of circulation } \\
\text { Diseases of respiratory tract } \\
\text { Violent deaths }\end{array}$ & $\begin{array}{l}117 \\
119 \\
111 \\
283 \\
137\end{array}$ & $\begin{array}{l}129 \\
112 \\
124 \\
176 \\
119\end{array}$ & $\begin{array}{r}82 \\
58 \\
94 \\
69 \\
116\end{array}$ & $\begin{array}{r}103 \\
88 \\
105 \\
153 \\
125\end{array}$ & $\begin{array}{r}127 \\
135 \\
131 \\
258 \\
68\end{array}$ & $\begin{array}{r}111 \\
91 \\
100 \\
129 \\
133\end{array}$ & $\begin{array}{r}84 \\
65 \\
88 \\
76 \\
117\end{array}$ & $\begin{array}{r}103 \\
92 \\
104 \\
151 \\
104\end{array}$ \\
\hline
\end{tabular}


Table 4 Observed and expected cases of malignant neoplasms 1958-79 for two categories of employment periods before age 80 after a latency time of 20 years

\begin{tabular}{|c|c|c|c|c|}
\hline \multirow[t]{3}{*}{ Type of neoplasm } & \multicolumn{4}{|c|}{ Employment period } \\
\hline & \multicolumn{2}{|c|}{$<2$ years } & \multicolumn{2}{|c|}{$\geqslant 2$ years } \\
\hline & Obs & Exp & Obs & $\operatorname{Exp}$ \\
\hline $\begin{array}{l}\text { All tumours } \\
\text { Lung cancer } \\
\text { Gastrointestinal cancer }\end{array}$ & $\begin{array}{r}13 \\
3 \\
3\end{array}$ & $\begin{array}{l}10 \\
1 \cdot 3 \\
1 \cdot 5\end{array}$ & $\begin{array}{r}15 \\
3 \\
0\end{array}$ & $\begin{array}{c}24 \\
3 \\
3 \cdot 6\end{array}$ \\
\hline
\end{tabular}

Table 2 shows the lung cancer mortality in various periods of employment time, with a requirement of 20 years latency time. The excess mortality is among those employed for the shortest period, whereas among those employed longer than five years there is only one case against 2.6 expected.

The tendency to increased mortality from various causes among short term employees persists independent of latency time (table 3 ). The overall cancer morbidity was similar to the national average (table 4). Again, short term employees suffered from a greater incidence of cancer. At least one deceased case of lung cancer could not be found in the National Cancer Registry, obviously due to incomplete data in this register. No case of mesothelioma has been reported.

\section{Discussion and review}

This cohort study of 1176 asbestos cement workers does not indicate any work related excess mortality, despite the fact that consideration has been given to different latency period requirements. Possible explanations of the non-positive outcome are (a) relatively low average levels of cumulative exposure to asbestos, $(b)$ the use chiefly of white asbestos in production, and (c) extremely few cigarette smokers. These possibilities will be discussed and related to findings in other mortality studies on asbestos cement workers.

Short term employees had a higher mortality rate from virtually all causes (not just work related ones) than long term employees. Such a pattern has also been observed in other cohorts ${ }^{6-9}$ and is perhaps conditioned by individual risk factors such as high consumption of tobacco and alcohol, which tend to be commoner among short term employees in some industries. ${ }^{10}$

The excess mortality among short term employees in this study was especially pronounced with regard to lung cancer, therefore we looked into the previous work of the deceased. Two of them had been on the docks, unloading sacks of asbestos to be sent to the plant. Such additional exposure could explain the overrepresentation of lung cancer mortality in the lowest exposure category. But the reduced mortality from lung cancer among those employed longer than five years remains unexplained, and further follow up time will be of value.

Smoking habits might influence the risk estimates but were not known for the entire cohort. In a subsample of the cohort who participated in a voluntary health examination in $1980,40 \%$ were smokers, $24 \%$ never-smokers, and $36 \%$ ex-smokers. The distribution is close to the national average, but participants in a voluntary health survey may not be representative of the whole cohort.

The validity of national death rates as a reference entity may be deficient and bias the estimates. The death rates for the county where the plant was located were not available. The age specific lung cancer incidence rates of the county were known, however, and averaged $108 \%$ of the national rates in 1975-80." The slight overestimation of the risk of lung cancer caused by this difference seems insignificant.

The median exposure of the cohort is not known but using the crude way of estimating from incomplete data referred to in the review (see below) the median exposure may be estimated as 10 fibre-years at the most. This comparatively low exposure, together with the predominance of chrysotile in the production, may explain the low relative risk for lung cancer.

Until recent years research into cancer incidence and mortality among asbestos cement workers has been scarce, but during the past five years six studies have been published. This motivates a review of these studies in reference to the findings in the Swedish study. Attempts have been made to estimate median exposure from data in the publications and expressing these as "fibre-years." This concentration-time unit has been used extensively in dose response calculations for other occupational groups exposed to asbestos. ${ }^{12}$

In 1979 a cohort study indicated that the incidence of lung cancer among asbestos cement workers in New Orleans increased with duration of employment and cumulative exposure, being at most about twice that expected. ${ }^{13}$ Everyone ever employed for at least one continuous month between 1942 and 1969 in asbestos cement plants in New Orleans were recruited. Seventy six per cent of the cohort had been employed during the 1940 s; $60 \%$ had an employment time of less than one year. Only $75 \%$ could be identified but the untraced were of middle age and are believed to have been alive. Half the untraced cohort members had had a transaction with the Social Security Administration in the early 1970 s. 
Estimations of dust exposure were based on sampling initiated in the 1950 s and recorded in million particles per cubic foot $\times$ years (mppcf-years). Estimations of the fibre content for each job and year were combined with work histories. The cumulative exposures of each subject included only the first 20 years of employment, which may have sharpened the dose response relation. The predominant fibre type was chrysotile but crocidolite constituted $3 \%$ and amosite $1 \%$ of the products, mainly in the production of pipes. If the factor for conversion from mppcf to fibre is taken as $2^{14}$ the mean cumulative exposure of the cohort appears from the tables to have been 70-100 fibre-years. With such a large proportion of short term employees, however, the median value is probably below 20 fibre-years. The general fibre level is given as $1-4$ fibres $/ \mathrm{ml},{ }^{15}$ which may be compared with the levels of 2-6 fibres $/ \mathrm{ml}$ at an asbestos cement plant in Nigeria. ${ }^{16}$

Mortality from lung cancer in the highest cumulative dust exposure groups was significantly raised (SMR 2.9-2.3), and the increase was most pronounced for the groups exposed to crocidolite (SMR $2 \cdot 4-3 \cdot 6)$. The analyses were made with different latency times, mostly 20 years. Two reference entities were used (the general populations of the United States and of Louisiana). The SMRs in the published report refer to the general population of the United States. As lung cancer rates are higher in Louisiana than in most states in the United States, the SMRs were reported to be lower when the local deaths rates were used for comparison. A case referent study was performed within the cohort that yielded a significant difference in dust exposure between cases and referents. A weakness of this study seems to be the relatively large loss to follow up.

A cohort study from an asbestos cement plant in Ontario, which began production in 1948, showed a considerable increase in mortality from lung cancer. ${ }^{17}$ The study group consisted of the 339 men who had been employed for ten or more years and had been hired before 1960 . These men were divided among three subgroups: 186 production workers exposed specifically to asbestos dust for at least 12 months, 55 maintenance workers, and 87 workers in mineral fibre operations without exposure to asbestos. Ninety six per cent of the men were followed up to 1980 .

The exposure data are reported to be excellent as the company maintained employment records that contained a chronological listing of job assignment for each employee. These records were matched with the exposure estimates based on membrane filter sampling starting in 1969 to provide estimates of the annual exposure of each production worker, but this was not possible for the maintenance workers. In the asbestos cement board operation chrysotile asbestos was the only type of asbestos used but in the pipe process both chrysotile and crocidolite asbestos were generally used in each batch. The exposure at this plant seems to have been high: willows operators were estimated to have been exposed to $40 \mathrm{fibres} / \mathrm{ml}$ in 1949 and $20 \mathrm{fibres} / \mathrm{ml}$ in 1969. Only the first 18 years were included in the calculations of cumulative exposure. The estimated mean exposure for the production workers was more than 100 fibre-years. The median exposure is probably about the same, as every man was employed for at least nine years and only a small fraction longer than 18 years.

The lung cancer death rate among the employees was compared with the mortality predicted from Ontario population rates. With a requirement of 20 years latency the SMR was 8.5 (17 observed against 2.0 expected) for production workers and 0.9 (1 observed against $1 \cdot 1$ expected) for unexposed workers. There were ten mesotheliomas in the cohort and also increases in gastrointestinal cancer and nonmalignant respiratory disease that were not statistically significant.

A cohort study of 1970 male and female asbestos cement workers in Wales who had been employed at least six months between 1936 and 1977 showed no increased mortality from any type of cancer. ${ }^{18}$ The follow up to the end of 1977 was successful in tracing $97 \%$ of the men and $95 \%$ of the women. The turnover was high as three quarters had worked in the factory for less than four years, more than half of the cohort for less than two years, and only 46 for more than 30 years. Nevertheless, the proportion of short term employees is less than in the New Orleans cohort.

Dust had been regularly measured since 1968 and during the 1970s the levels were always below 2 fibres $/ \mathrm{ml}$, most below 1 fibre/ml. Before 1968 the levels were estimated to range between $0 \cdot 1$ and more than $20 \mathrm{fibres} / \mathrm{ml}$. The average exposure is not given, but a rough estimate might put the median exposure at about 10-20 fibre-years. Only chrysotile is reported to have been used. In all, 28 lung cancers were observed, including one case of adenocarcinoma and two mesotheliomas compared with 33 expected. With a latency time of 15 years, 24 deaths were observed against 25.8 expected. The expected number of deaths was derived from sex, age, class, and calendar year specific death rates for England and Wales. There was, however, no stratification for exposure time which is a shortcoming, as subjects with short exposure might conceal a possible risk among the long term exposed subjects.

A Belgian study reported in 1980 indicated no 
increased mortality from lung cancer. ${ }^{19}$ The cohort consisted of 1963 male workers employed at least 12 months during 1963-77. There are no comments on the proportion followed up. Fibre counts were available for 1970-6, and individual exposure was expressed in fibre-years based on job histories. The death rates from lung cancer were close to the expected rates, calculated from the national specific death rates for Belgium. The analyses were made without consideration of latency time or exposure strata. It is not possible to draw any firm conclusions from this study.

Also in 1980 an Austrian study of cancer incidence among workers exposed to asbestos cement was reported. ${ }^{20}$ All enlisted men employed for at least three years between 1950 and 1960 at an asbestos cement plant and born in 1910 or earlier comprised the cohort of 314 men. A cohort from the same rural area of 243 cement workers was used for reference. Furthermore, a comparison was made with the general population. Exposure data were not reported, nor the degree of follow up, and the data analyses were made without requirement of latency time. The asbestos cement cohort had a $50 \%$ higher death rate from lung cancer compared with the referent cohort. Both cohorts, however, had low death rates compared with the general population.

The most obvious explanation of the differences between the various studies is the degree and time of exposure. The Ontario cohort, which had the highest risk estimates, was heavily exposed and included only long term employees. The production workers had an estimated median exposure of about 100 fibre-years. ${ }^{17}$ The New Orleans cohort had lower exposure and a high turnover but showed a significant increase among the group with the highest cumulative exposures despite limited follow up. ${ }^{13}$ The Welsh cohort also had a high turnover and, as no separate figures were given for the long term employed subcohort, any risk associated with the exposure would be diluted. ${ }^{18}$ The Swedish cohort which we studied was estimated to have been less exposed and had a much lower turnover than the New Orleans cohort.

Another possible explanation of the differences in lung cancer mortality is fibre type. Chrysotile is reported to have been used exclusively in the case of the non-positive studies (18 and our study), but in the case of the two positive studies there had in addition been regular handling of crocidolite, amosite, or both. ${ }^{13} 17$

A distinctly lower risk of lung cancer after exposure to chrysotile than to amphiboles is suggested in a study of two groups of women manufacturing gas masks. ${ }^{21}$ No excess risk of lung cancer could be associated with manufacturing gas masks containing chrysotile but a $2 \frac{1 / 2}{2}$-fold excess of lung cancer was observed among the women manufacturing gas masks containing crocidolite. Two other studies of workers manufacturing friction materials give further support to the assumption of an appreciably lower risk of lung cancer after exposure to chrysotile than to amphiboles. ${ }^{822}$

Tentative conclusions from this review, corroborated by the findings in our study, indicate that long term employment in high concentrations of asbestos fibre giving a median cumulative exposure of 70 100 fibre-years increases the risk of lung cancer considerably whereas exposure with a median exposure of about 10-20 fibre-years does not. Furthermore, the risk for lung cancer seems to be relatively low when only chrysotile is used in the production.

We thank the former union representative Torbjörn Waséll for completion of the personnel registry; Mss I Fagerlund and I-L Bryngelsson, research assistants, for subject tracing and data processing; and Mss C Söderqvist for preparing the manuscript. Professor D Wegman, UCLA, made constructive comments on the manuscript. This study was supported by the Swedish Work Environment Fund (No 82/ 0217).

Requests for reprints to Carl-Göran Ohlson, Department of Occupational Medicine, Medical Center Hospital, S-701 85 Örebro, Sweden.

\section{References}

Advisory Committee on Asbestos. Health and Safety Commission. Final report. Vol 1. London: HMSO, 1979.

${ }^{2}$ Baeten J, Helsen J, Deruyttere A. Nature, structure, and properties of asbestos cement dust. $\mathrm{Br} J$ Ind Med 1980;37:33-41.

${ }^{3}$ Ohlson C-G, Hogstedt C. A cohort study on mortality among Swedish asbestos cement workers. International Symposium on Prevention of Occupational Cancer, 21-27 April 1981, Helsinki. Geneva: ILO, 1982. (Occupational Safety and Health series 46.)

${ }^{4}$ Anjou C-G, Andersson K, Axelson O, Edling C, Samuelsson P-J, Wigertz O. A computer system for occupational health epidemiology. Linköping: Department of Medical Engineering, Linköping University, 1980.

${ }^{5}$ Ohlson C-G, Rydman T, Sundell L, Bodin L, Hogstedt C. Decreased lung function in long-term asbestos cement workers: a cross-sectional study. Am J Ind Med 1984;5:359-66.

- Acheson ED, Gardner MJ, Pannett B, Barnes HR, Osmond C, Taylor CP. Formaldehyde in the British chemical industry. Lancet 1984;i:611-6.

' Berrino F, Crosignani P, Aresini GA, Guerreri MC, Vigliani EC. Mortality study of asbestos workers at the Balangero chrysotile mine. (Abstract to the VIth International Pneumoconiosis Conference. ILO, Bochum: 1983.) Bochum: BergbauBerufsgenossenschaft, 1984.

${ }^{8}$ McDonald AD, Fry JS, Woolley AJ, McDonald JC. Dust exposure and mortality in an American chrysotile asbestos friction products plant. Br J Ind Med 1984;41:151-7. 
' Seidman H, Selikoff IJ, Hammond EC. Short-term asbestos work exposure and long-term observation. Ann NY Acad Sci 1979;330:61-89.

${ }^{10}$ Fox AJ, Goldblatt PO. Longitudinal study. Socio-demographic mortality differentials. A furst report on mortality in 1971-1975 according to 1971 census characteristics, based on data collected in the OPCS longitudinal study. London: Office of Population Censuses and Surveys, 1982.

"Cancer Registry. Cancer incidence in Sweden, 1975-80. Stockholm: National Board of Health and Welfare, 1983.

${ }^{12}$ Nicholson WJ, Perkel G, Selikoff IJ. Occupational exposure to asbestos: population at risk and projected mortality-1980 2030. Am J Ind Med 1982;3:259-311.

${ }^{13}$ Weill H, Hughes J, Waggenspack C. Influence of dose and fiber type on respiratory malignancy risk in asbestos cement manufacturing. Am Rev Respir Dis 1979;120:345-54.

${ }^{14}$ Lynch JR, Ayer HE, Johnson DL. The interrelationships of selected asbestos exposure indices. Am Ind Hyg Assoc J 1970;31:598-604.

is Hammad YY, Diem J, Weill H. Evaluation of dust exposure in asbestos cement manufacturing operations. Am Ind Hyg Assoc J 1979;40:490-5.

${ }^{16}$ Oleru UG. Pulmonary function of control and industrially exposed Nigerians in asbestos, textile, and toluene diisocyanate-foam factories. Environ Res 1980;23:137-48.

${ }^{17}$ Finkelstein MM. Mortality among long term employees of an Ontario asbestos cement factory. Br J Ind Med 1983;40:13844.

${ }^{18}$ Thomas HF, Benjamin IT, Elwood PC, Sweetnam PM. Further follow-up study of workers from an asbestos cement factory. Br J Ind Med 1982;39:273-6.

${ }^{19}$ Lacquet LM, van der Linden L, Lepoutre J. Roentgenographic lung changes, asbestosis and mortality in a Belgian asbestoscement factory. In: Wagner JC, ed. Biological effects of mineral fibres. Lyon: International Agency for Research on Cancer, 1980. (Scientific publications No 30.)

${ }^{20}$ Haider M, Neuberger M. Comparison of lung cancer risks for dust workers, asbestos-cement workers and control groups. In Wagner JC, ed. Biological effects of mineral fibres. Lyon: International Agency for Research on Cancer, 1980. (Scientific publications No 30 .)

${ }^{21}$ Acheson ED, Gardner MJ, Pippard EC, Grime LP. Mortality of two groups of women who manufactured gas masks from chrysotile and crocidolite asbestos: a 40 year follow-up. $\mathrm{Br} \mathrm{J}$ Ind Med 1982;39:344-8.

${ }^{22}$ Berry G, Newhouse ML. Mortality of workers manufacturing friction materials using asbestos. Br J Ind Med 1983;40:1-7. 